\title{
Lacan y el Barroco
}

\section{Lacan and the Baroque}

\author{
IGNACIO IRIARTE \\ Universidad Nacional de Mar del Plata / CONICET \\ iriarteignacio@yahoo.com.ar
}

Recibido: 05-01-2011

Aceptado: 04-03-2013

\section{Resumen}

En este trabajo describo algunos aspectos de la interpretación de Lacan sobre el Barroco y su concepción sobre los vínculos entre la palabra y la imagen. Para esto distingo tres lecturas sobre la cultura del siglo XVII. La primera, que pertenece al primer período de su enseñanza, se organiza a partir de lo que Massimo Recalcati denomina una "estética del vacío". La segunda, formulada en el seminario El objeto del psicoanálisis, se estructura a partir de la mirada. La tercera, establecida en el seminario Aun, tiene como eje el cuerpo y las reflexiones sobre lo real.

Palabras clave: imagen, palabra, Barroco, Lacan.

\begin{abstract}
This paper describes some aspects of Lacan's interpretation on the Baroque and his conception of the links between word and image. To do this I distinguish three different readings of seventeenth-century culture. The first, which belongs to the first period of his teaching, is organized from what Massimo Recalcati called an "aesthetics of emptiness". The second of his lectures, given at the seminar The object of psychoanalysis, is structured from the conceptualization of the gaze. The third, established in the seminar Encore, is centered on the body and the reflections on the real.
\end{abstract}

Keywords: Image, word, Baroque, Lacan. 


\section{Introducción: Lacan y el Barroco ${ }^{1}$}

No es una novedad afirmar que Lacan elaboró una de las propuestas teóricas más importantes sobre los vínculos entre la palabra y la imagen. Su obra está tan atravesada por esa relación tensa que incluso un lector que toma por primera vez alguno de los tomos de los Escritos y lo hojea despreocupadamente antes de comprarlo puede estar seguro, después de dejarlo en el estante o dirigirse para realizar la compra, de que a Lacan le interesó decir tanto como mostrar mediante esquemas y gráficos sus ideas sobre el sujeto. Tampoco es una novedad destacar que uno de sus apoyos recurrentes para abordar estos vínculos es el Barroco. Para Lacan, la cultura del siglo XVII tiene un profundo interés en tanto expone una idea del sujeto semejante a la de Freud.

En este trabajo me propongo describir algunos aspectos de la relación de Lacan con el Barroco y de su concepción sobre los vínculos entre la palabra y la imagen. Para abordar el tema, en las páginas que siguen destaco que a lo largo de su obra propone tres interpretaciones de ese período. La primera de ellas, situada en el primer tramo de sus trabajos, coincide con su profundización del concepto de narcisismo. En esta etapa, y para retomar la propuesta de Massimo Recalcati, Lacan entiende el Barroco como una "estética del vacío", en tanto demuestra que el hombre es un juego de representaciones que bordean el agujero de lo real ${ }^{2}$. En una segunda etapa, centrada en los seminarios Los cuatro conceptos fundamentales del psicoanálisis (1964) y El objeto del psicoanálisis (1965-1966), Lacan propone una reconsideración teórica de las relaciones entre lo simbólico y lo real y establece una particular conceptualización de la mirada. En este contexto, aborda el Barroco a través de Las Meninas de Diego Velázquez. Finalmente, en Aun (1972-1973), Lacan se ocupa del goce y las dos vías de la sexuación. En el transcurso de este seminario, introduce su análisis más completo del Barroco, entendiéndolo como un arte que demuestra la incidencia del Otro en lo corporal.

Estas reflexiones de Lacan tienen un interés intrínseco. Entre otras cosas, abren puntos de vista insoslayables para el estudio del arte y esclarecen los andamiajes a

\footnotetext{
${ }^{1}$ Este trabajo le debe mucho a las orientaciones que Alfredo Cosimi me brindó generosamente para la lectura de Lacan. Quisiera expresarle, entonces, mi mayor gratitud.

2 Recalcati, M., Las tres estéticas de Lacan, Buenos Aires, Ediciones del cifrado 2006. El autor señala que Lacan propone otras dos estéticas: la "estética de la anamorfosis" y la "estética de la letra". En este trabajo considero que Lacan lee el siglo XVII sin seguir estrictamente esta segmentación. Por esta razón, no me refiero a la "estética de la letra". Por otra parte, aunque su segunda lectura del Barroco coincide en general con la "estética de la anamorfosis", prefiero no utilizar ese concepto porque, como veremos más adelante, las consideraciones estéticas de esos años exceden la cuestión puntual de la anamorfosis y, además, porque el concepto se puede prestar a confusión, dado que en La ética del psicoanálisis Lacan se refiere al Barroco como estética del vacío, presentando como ejemplo una anamorfosis.
} 
partir de los cuales se articulan las palabras y las imágenes que determinan al sujeto. También permiten comprobar una segunda cuestión: desde que, entre fines del siglo XIX y principios del XX, empezó a valorarse el arte del Barroco, se convirtió en un objeto que, tanto por su atractivo como por las resistencias que genera, ha acompañado y en muchos sentidos orientado la formación del pensamiento moderno. El tema desborda este trabajo, pero las líneas que siguen intentan contribuir aunque sea mínimamente a él.

\section{El Barroco del vacío}

Si comparamos la obra de Lacan con una obra de teatro, podemos afirmar que el Barroco aparece recién hacia la mitad de la función. Este primer tramo al que nos vamos a abocar es representativo de lo que acabo de decir. En los Escritos, tenemos que saltear varias páginas del segundo tomo para encontrar, en «Observación sobre el informe de Daniel Lagache», una referencia clara sobre el Barroco. Pero el artículo, publicado originalmente en 1961, es la conclusión de un largo desarrollo teórico, que tiene su inicio en «El estadio del espejo como formador de la función del yo» (1949)3. De acuerdo con esto, para comprender el lugar que ocupa el Barroco en este primer tramo de su obra, es imperioso remontar sus reflexiones desde ese texto inicial.

De acuerdo con «El estadio del espejo», entre los seis y los dieciocho meses de edad el infante tiene una experiencia fragmentada del cuerpo y se encuentra en una dependencia tal de su madre que no concibe una frontera nítida que lo separe de ella. Demuestra, asimismo, un gran atraso motriz en comparación con otros mamíferos (no puede mantenerse en pie ni alimentarse por sí mismo). Sin embargo, los supera en un aspecto central: cuando se acerca a un espejo, logra reconocerse en la imagen que éste le devuelve. Esto tiene una enorme importancia, porque es a partir del reflejo que concibe su cuerpo como unidad y logra instalarse en el mundo. Se trata, pues, de la primera identificación, que será crucial para el resto de su experiencia. Cabe agregar, además, que esta imagen que le devuelve el espejo, y que le da el ropaje para unificar su cuerpo, no tiene consistencia alguna (se trata de un juego de luces que rebotan en la superficie) y resulta asimismo alienante. Escribe Lacan:

la forma total del cuerpo, gracias a la cual el sujeto se adelanta en un espejismo a la maduración de su poder, no le es dada sino como Gestalt, es decir en una exterioridad donde sin duda esa forma es más constituyente que constituida, pero donde sobre todo

\footnotetext{
3 Por otra parte, Lacan asegura que presentó una primera versión en el Congreso de Marienbad de 1936. Al respecto, ver Lacan, J., Escritos, tomo 1, Buenos Aires, Siglo XXI, 1988, p. 61.
} 
le aparece en un relieve de estatura que la coagula y bajo una simetría que la invierte, en oposición a la turbulencia de movimientos con que se experimenta a sí mismo animándola. 4

A lo largo de Los escritos técnicos de Freud (1953-1954), primero de sus seminarios, Lacan profundiza esta conceptualización del estadio del espejo. Para esto, en la clase del 24 de febrero de 1954 presenta a la audiencia el siguiente experimento de óptica, que toma de la Optique et photométrie dites géometriques de Henri Bouasse ${ }^{5}$ :

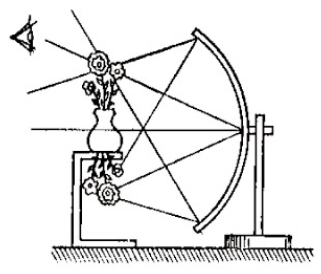

El semicírculo de la derecha es un espejo cóncavo. Frente a él, hay una caja, en la cual se encuentra encerrado un ramo de flores, colocado de manera invertida. Sobre la caja, un florero vacío. El aparato supone que si un sujeto, representado por el ojo de la izquierda, se sitúa en un ángulo adecuado, verá aparecer las flores, como si éstas se encontraran efectivamente en el florero. En su simpleza, el modelo muestra dos cosas: en primer lugar, que existe una estricta separación entre el mundo real y el mundo imaginario, en la medida en que lo real, oculto en la caja, únicamente se ve gracias al mundo virtual del espejo; en segundo lugar, que existe una articulación, en tanto la cuestión pasa por cómo la imagen de las flores se coloca en el florero. Lacan utiliza el artefacto para hacer un planteo más completo del estadio del espejo. Invierte los objetos representados (coloca el florero dentro de la caja y las flores sobre ella) y propone que el florero es el cuerpo y las flores son los diferentes objetos que encuentra y a partir de los cuales puede pensarse. En este sentido, el artefacto demuestra lo que sucede en la primera constitución del yo. El cuerpo real del sujeto, del cual únicamente tiene una experiencia fragmentada, se presenta como totalidad gracias a la imagen en el espejo. De manera correlativa, el artefacto revela que todo interés que el niño pone en los objetos es siempre una proyección de una parte de su imagen sobre ellos.

Durante la descripción del modelo, Lacan pone un especial énfasis en que la ilusión se produce si el sujeto mira desde un lugar en particular. Puede ser, por ejemplo, que se encuentre demasiado atrás o demasiado adelante, entonces no tendría

\footnotetext{
4 Ibidem, 87-88.

5 En ese seminario, Lacan no revela esta referencia bibliográfica. Sí lo hace en «Observación sobre el informe de Daniel Lagache». Cf. Lacan, J., Escritos, tomo 2, Buenos Aires, Siglo XXI, 1999, p. 652.
} 
acceso a la imagen. Traducido a la conceptualización lacaniana, si el sujeto no se situara en el lugar adecuado, no lograría articular el mundo imaginario y el mundo real, lo cual significa que no tendría la posibilidad de constituir una imagen propia y se perdería en una continuidad confusa de cosas. Pero, aunque el modelo representa bien la propuesta de Lacan, le falta algo crucial. Como lo demuestra la más mínima experiencia con un infante, es usual que cuando éste mira su reflejo se dé vuelta para buscar a un adulto que ratifique que ése que está ahí adelante es él. En el juego de su mirada, hay siempre una segunda mirada que anuda el cuerpo a la imagen. Para demostrar correctamente esta cuestión, en la clase del 24 de marzo Lacan produce un modelo óptico más complejo, que retoma luego en «Observación sobre el informe de Daniel Lagache». Para mayor comodidad, reproduzco el esquema completo, en el cual ya se encuentran las letras del álgebra que Lacan creó luego de su lectura de Saussure:

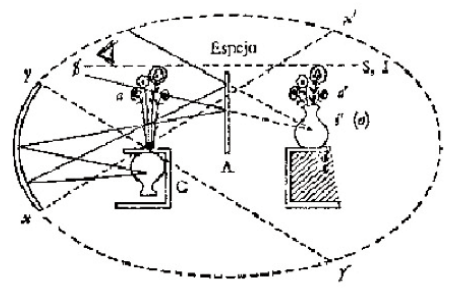

En Los escritos técnicos de Freud, no aparecen las simbolizaciones expresadas mediante la "A" y las diferentes formas de la letra "a". Tampoco el sujeto tachado, al lado del ojo. Pero Lacan formula de manera muy clara lo que esas letras van a venir a plantear cuando retome el modelo a partir de los años sesenta. El jarrón sigue representando el cuerpo, en tanto resulta inaccesible para el sujeto sin la mediación de la imagen. Las flores son, nuevamente, los objetos. Pero ahora la ilusión se produce gracias al enfrentamiento entre el espejo cóncavo y el espejo plano. Estos cruces de miradas deben entenderse como un modelo para representar la superación del estadio del espejo, pero no en el sentido de que éste se elimine, sino en tanto la relación imaginaria queda subordinada a otra cosa. Esa otra cosa es lo que viene a representar el espejo plano. En Los escritos técnicos de Freud, ese espejo es el Otro, lugar desde el cual el infante obtiene la confirmación de que la imagen que tiene delante de él es suya. Por esta razón, en el vértice opuesto al lugar del sujeto, identificado con las letras S e I, Lacan coloca la mirada del adulto. Base para el Ideal del yo, esa mirada aparece inicialmente como "rasgo unario": rasgo, porque no se trata de la totalidad del Otro, sino de su mirada, partición de la realidad que indica, por otra parte, que pertenece al orden del significante; unario, porque se trata del significante primero, a partir del cual se van a constituir los demás. El modelo óptico demuestra, así, que la identificación imaginaria con los objetos está sosteni- 
da sobre la base de la identificación simbólica que el sujeto encuentra en la mirada del Otro. Como se trata del primer significante, esa mirada está perdida, porque no hay un significante previo desde el cual comprenderla. En el modelo, Lacan representa esa borradura al colocar la mirada por encima del espejo, por lo tanto fuera del campo visual que el sujeto obtiene de él. Asimismo, en tanto regula la captura imaginaria, este significante primero orientará todas las elecciones de su vida. Para Lacan, el hombre se estructura, pues, sobre la base de un juego de miradas, cuyo fundamento permanece inaccesible a él. Por una parte, se vincula con la realidad a través de la imagen que le devuelven los objetos y, por la otra, se orienta a partir de la mirada mediante la cual fue introducido en el mundo del lenguaje6.

Como si buscara hacer un resumen de este largo desarrollo teórico, Lacan presenta las diferentes etapas del modelo óptico en «Observación sobre el informe de Daniel Lagache». Casi al final del texto, se refiere al siglo XVII:

Juegos de la orilla con la onda, observémoslo, con que ha encantado siempre, de Tristan l'Hermite hasta Cyrano, el manierismo preclásico, no sin motivación inconsciente, puesto que la poesía no hacía con ello más que adelantarse a la revolución del sujeto, que se connota en filosofía por llevar a la existencia a la función de atributo primero, no sin tomar sus efectos de una ciencia, de una política y de una sociedad nuevas.

Las complacencias del arte que las acompañan, ¿no se explican en el precio atribuido en la misma época a los artificios de la anamorfosis? Del divorcio existencial en que el cuerpo se desvanece en la espacialidad, pues esos artificios que instalan en el soporte mismo de la perspectiva una imagen oculta revocan la sustancia que se ha perdido en ella. ${ }^{7}$

En esta primera etapa de sus reflexiones teóricas, Lacan se interesa por el siglo XVII debido a la importancia que éste le otorga a los espejos, los disfraces y las simulaciones. No se preocupa todavía por la carga religiosa del período, que, como veremos, más tarde va a tomar un lugar central en sus reflexiones, sino que se deslumbra porque esa época entiende que el hombre es un personaje en la tragicome-

\footnotetext{
6 En Los escritos técnicos de Freud, Lacan demuestra el poder explicativo del modelo óptico a partir de un caso que Melanie Klein presenta en «La importancia de la formación del símbolo en el desarrollo del yo». En ese texto, Klein describe su experiencia con Dick, un chico de cuatro años, que tiene el intelecto de un niño de poco menos de dos. El paciente cuenta además con un vocabulario muy pobre y un registro imaginario también limitado, razón por la cual se enfrenta a una realidad prácticamente desnuda. Pero Klein descubre que, a pesar de todo, Dick juega con un trencito y una estación. A partir de esto, interviene diciéndole que él es el trencito y la madre, la estación. Para Lacan, al introducir estas simbolizaciones, coloca al chico en el mundo de la palabra y establece una serie de puntos de referencia a partir de los cuales puede contemplarse e ir constituyendo su yo. Para decirlo de otro modo, la terapeuta se sitúa como el espejo plano, dándole la inclinación adecuada para orientarlo hacia ese lugar. Al respecto, cf. Lacan, J., El seminario. Libro I. Los escritos técnicos de Freud, Buenos Aires, Paidós, 1981.
}

7 Lacan 1999, op. cit. (nota 5), p. 660. 
dia de la vida. A partir de este descubrimiento, la extensa reflexión que había comenzado con «El estadio del espejo» articula con el siglo XVII. Como señala el mismo Lacan, su desarrollo teórico sobre los espejos, formado él mismo sobre la base de un torcimiento manierista del narcisismo de Freud y el modelo óptico de Henri Bouasse, reencuentra pues la idea barroca de que el hombre es una superposición de representaciones que se disuelven en el espacio como se desvanece el espejismo del agua cuando avanza en el desierto el que tiene sed.

De acuerdo con la conceptualización de Recalcati, el Barroco aparece en esta época como una "estética del vacío". Por esta razón, es importante reparar en el pasaje en el cual Lacan se refiere a los "artificios de la anamorfosis". En primer lugar, porque aunque Recalcati utiliza el concepto para referirse a una estética posterior, preocupada por la mirada como objeto $a$, en este contexto todavía emplea la palabra para referirse a la superposición de representaciones en la cual se disuelve el ser humano. En segundo lugar, porque la anamorfosis es clave para completar la idea que Lacan se forja del Barroco. En La ética del psicoanálisis, seminario que dictó entre 1959 y 1960, es decir, en los mismos años en los que hizo la redacción definitiva de «Observación sobre el informe de Daniel Lagache», Lacan subraya en este sentido la importancia de la anamorfosis durante el siglo XVII. En la clase del 3 de febrero de 1960 introduce el tema, recordando que se trata de un tipo de pintura en la cual el espectador ve una imagen deformada, que se corrige cuando cambia de perspectiva. Anuncia, luego, que va a traer un ejemplo: un espejo cilíndrico en el cual, al acercarle un papel que contiene lo que parece una mancha, se forma un cuadro de Rubens. Entonces dice:

el retorno barroco a todos los juegos de la forma, a todos esos procedimientos, entre los que se cuenta la anamorfosis, es un esfuerzo para restaurar el verdadero sentido de la búsqueda artística -los artistas se sirven del descubrimiento de las propiedades de las líneas para hacer resurgir algo que esté allí donde uno no sabe ya qué hacer- hablando estrictamente, en ningún lado.

El cuadro de Rubens que surge en el lugar de la imagen ininteligible muestra bien de qué se trata -se trata, de manera analógica o anamórfica, de volver a indicar que buscamos en la ilusión algo en lo que la ilusión misma de algún modo se trasciende, se destruye, mostrando que sólo está allí en tanto que significante. ${ }^{8}$

La anamorfosis es un significante y ese significante que se disuelve con un golpe de vista representa, como el modelo óptico, la falta de consistencia del sujeto. Pero en el marco de las afinidades que Lacan halla entre el psicoanálisis y el Barroco, la importancia de este seminario se encuentra en que en él revela además que si las imágenes y las palabras se forman sobre el vacío, es porque en ese vacío

8 Lacan, J., El Seminario. Libro 7. La ética del psicoanálisis, Buenos Aires, Paidós, 2000, p. 168. 
se encuentra la Cosa, madre primordial e irrepresentable, núcleo de lo real que perfora lo simbólico y lo imaginario. El sujeto se afirma en su imagen a través del significante de la mirada del Otro y todo esto se articula sobre esa imposibilidad. Como señala Lacan, el arte es una forma de bordear este hueco irrepresentable. En este marco, el Barroco tiene un valor suplementario, porque ese período, desde la cultura, el arte, la política y la religión, se propuso como meta principal poner de manifiesto que el hombre es un espejismo que se levanta sobre el vacío que produce la pérdida irrecuperable de lo real.

\section{El Barroco de la mirada}

Después de La ética del psicoanálisis, Lacan abandona la Cosa y comienza a plantear lo real a partir del objeto $a$. Como se sabe, con ese concepto denomina una serie de objetos que inicialmente se encuentran en la imagen especular que une al infante con la madre. Es el seno que lo alimenta, las heces que regala, la voz que le habla, la mirada que lo mira. Con la entrada en el lenguaje, esos objetos se pierden, como si el significante los cortara del cuerpo del sujeto. Así, se constituyen en aquello que va a buscar en los otros más allá de lo que esos otros son. Con este avance teórico, Lacan transforma su concepción de lo imaginario, lo simbólico y lo real y radicaliza los aportes sobre la mirada que había hecho a través del modelo óptico. A partir de estas reconsideraciones, en Los cuatro conceptos y en El objeto del psicoanálisis elabora un complejo análisis de la pintura. En este marco, vuelve al siglo XVII a través de Las Meninas. Pero, como antes, lo hace al final de un extenso desarrollo, al que nos abocaremos para comprender este segundo abordaje del Barroco.

Para introducirnos en la conceptualización lacaniana de este período, es instructivo volver a «Observación sobre el informe de Daniel Lagache». Como vimos, el modelo óptico representa la relación imaginaria que el sujeto mantiene con los objetos que halla a lo largo de su vida. La clave se encuentra, a su vez, en que esa relación se determina a partir del rasgo unario que constituye la mirada del Otro. Si nos detenemos en el modelo a partir de Los cuatro conceptos, podemos ver que el aporte de esta etapa se encuentra en que Lacan le da una precisión mayor al rasgo unario. En nuestra breve descripción del modelo óptico, vimos que el rasgo unario coagula la identificación imaginaria e introduce al sujeto al mundo del lenguaje. Pero ahora podemos percatarnos de que el rasgo unario también es una forma de desalojar la mirada. En primer lugar, el hecho de que el infante se reconozca a partir de esa mirada, hace que ella se separe de su cuerpo y provenga del exterior. Asimismo, en tanto se trata de un significante, el rasgo unario tiene el efecto de representar la mirada, pero a la vez de desalojarla en su real dimensión. Por eso, Lacan la conceptualiza como objeto $a$, parte que cae de la imagen del cuerpo, pero también que el 
lenguaje desplaza, volviéndola irrecuperable. En este sentido, el sujeto ve el mundo, es decir, ve a los otros con los que interactúa; pero, a la vez, lo atraen o les son indiferentes, en primer lugar porque el Otro lo mira y en segundo lugar porque busca en ellos esa mirada perdida. En este sentido, el campo visual se estructura a partir de la diferencia entre la visión y la mirada.

En Los cuatro conceptos, Lacan presenta estas ideas apoyándose en estos dos esquemas triangulares:

Objeto

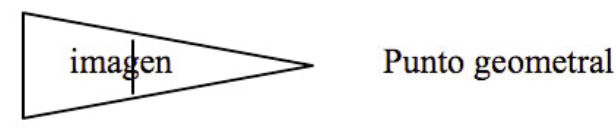

Punto luminoso

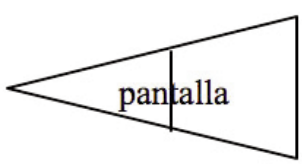

Cuadro

El primer triángulo representa al sujeto de la visión. El hombre, situado en el punto geometral, se coloca ante la realidad y obtiene una imagen, sin alcanzar nunca la crudeza del objeto. Se trata del sujeto kantiano, que siempre ve los fenómenos, pero nunca la cosa en sí. El segundo triángulo representa lo que sucede con la mirada. En el punto luminoso, se encuentra la mirada del Otro. Como vimos, por un lado se trata de un significante que determina la relación imaginaria y por el otro de la mirada como objeto $a$, que ese significante destituye. Entre ese punto y lo que denomina cuadro, Lacan sitúa una pantalla. Esta pantalla representa el fantasma del sujeto, es decir, el guión escénico, inconsciente, mediante el cual interpretó inicialmente la mirada del Otro. En el registro escópico, estos dos triángulos están integrados, de manera tal que el objeto coincide con la mirada, el sujeto con el cuadro y la imagen con la pantalla. Esto significa que el sujeto ve porque el Otro lo mira. Nuevamente, esto quiere decir dos cosas. En primer lugar, el sujeto encuentra otros sujetos que le resultan encantadores, odiosos o indiferentes porque, de manera inconsciente e inevitable, mantiene una relación imaginaria, de identificación o rivalidad, orientada por la mirada del Otro. En segundo término, en tanto el sujeto busca esa mirada perdida, el objeto $a$ se convierte verdaderamente en el foco de luz que ilumina determinados objetos y oscurece otros, porque al fin y al cabo se puede interesar por ellos si éstos pueden representar, aunque sea, una esquirla de esa mirada. Por esta razón, la imagen del mundo, como la imagen del espejo en el modelo óptico, está siempre estructurada por el fantasma mediante el cual el sujeto interpretó la mirada del Otro. Y, como resultado de todo esto, el sujeto se coloca en el cuadro de esa fantasía: se convierte en el personaje de una obra de teatro hecha para ese espectador primordial e irremediablemente perdido detrás del lenguaje.

En este juego óptico, la pintura está llamada a cumplir un rol central. Para comprenderlo, podemos ordenar los elementos compositivos que, desde Los cuatro con- 
ceptos a El objeto del psicoanálisis, Lacan destaca en los cuadros figurativos. En este tipo de cuadros, el pintor representa un fragmento del mundo. Para hacerlo, elige un punto de fuga, en el cual confluyen todas las líneas proyectivas. Este punto, además, indica el punto de observación, es decir, la distancia que el espectador debe mantener respecto del cuadro para que, situando sus ojos a la altura del punto de vista, perciba con exactitud la perspectiva. Si enfocamos ahora el momento en el que el pintor está trabajando, podemos ver que tiene en los ojos un fragmento de mundo y lo exterioriza, porque copia los colores que ve, pero también porque compone un punto de vista implícito en el cuadro desde el cual se imagina representar. Para Lacan, con estos elementos, la pintura cumple un rol teórico central. Como vimos, el sujeto contempla el mundo, se interesa por algún aspecto de él, en tanto la imagen que toma está articulada por el fantasma. La pintura da un paso importante precisamente porque exterioriza esta pantalla-imagen. Esto se debe a que el pintor objetiva su visión en un cuadro, que por otra parte se puede colgar, vender e incluso destruir. Pero para hacer esto exterioriza además una mirada. Reconocemos la mirada de un pintor, incluso la mirada de una época de la pintura, porque en sus cuadros hay un estilo particular que caracteriza la visión de mundo que ese pintor o esa época tienen. Sin embargo, aunque el pintor puede representarlo todo, no puede representar su mirada en sí, del mismo modo que nuestro ojo no puede verse a sí mismo cuando ve. Para Lacan, éste es el primer aporte teórico de la pintura: la mirada en sí misma está fuera del campo de lo visual. Para afianzar este aporte, destaca que el punto de fuga, el punto de vista del pintor y el punto de observación están unidos por una recta imaginaria que corre paralela al piso. De acuerdo con esto, la mirada del pintor está representada por el punto de fuga, como lo explicita Jan van Eyck en el famoso El matrimonio Arnolfini (1434), colocando un espejo en el cual él mismo aparece representado. Pero ésa no es más que una máscara, porque en ese lugar van Eyck no puede pintar el acto de pintar este cuadro que vemos pintado. El punto de fuga es un punto en el infinito y, como está en el infinito, es irrepresentable como tal. En el cuadro, como dice Lacan, el artista depone la mirada: la bordea, la sugiere, la intuye, le da un valor estructurante, en tanto se trata de aquello que organiza la representación, pero en ese acto reconoce que no la puede representar. Por lo tanto, la pintura exterioriza la pantalla-imagen, pero con todas las condiciones que ésta tiene. Se trata de una imagen del mundo que se define por el hecho de que es un no-Todo, una representación a la cual siempre le falta la representación de la mirada. Por eso, en Los cuatro conceptos coloca dos fórmulas: "La mirada es el objeto a en el campo de lo visible" y, tras una llave, "en la naturaleza como = ($\Phi) "$, es decir, "en su función de simbolizar la falta central del deseo"9.

9 Lacan, J., El Seminario. Libro 11. Los cuatro conceptos fundamentales del psicoanálisis, Buenos Aires, Paidós, 2005, p. 112. 
En este primer abordaje, el cuadro demuestra que la mirada es irrepresentable. Conceptualmente, no se trata todavía de la mirada del Otro, sino de una cuestión simple y experimentable cotidianamente: cuando vemos no nos vemos. Pero Lacan da un paso teórico más. En primer lugar, en tanto el pintor no puede representar su mirada, el cuadro demuestra que hay una estricta separación entre la visión (lo que ve el pintor cuando representa el mundo) y la mirada (el lugar desde donde podría verse al pintar). Esta separación significa, en segundo lugar, que esa mirada únicamente podría provenir desde el exterior. Por último, aunque al principio parece accesoria, el pintor representa esa mirada en el punto de fuga, es decir, la convierte en el eje a partir del cual se organiza lo que ve. En este sentido, en tanto la mirada proviene desde el exterior y a la vez estructura el campo visual, Lacan concluye que el cuadro en perspectiva demuestra que el sujeto ve gracias a que la mirada perdida del Otro organiza lo visual ${ }^{10}$. Por esta razón se puede afirmar que existe una mirada compartida entre los pintores de una época determinada. ¿Qué comparten sino una mirada que aparece en sus cuadros y que también organiza ese cuadro que es la sociedad en la que se incluyen y en la que participan como cualquier otro de sus integrantes? Lacan demuestra este hecho a partir de los iconos religiosos. En los mosaicos bizantinos, por ejemplo, Cristo nos mira. No es una metáfora: efectivamente Cristo está mirando hacia donde estamos parados. Pero esto no lo dice todo, porque "el valor del icono estriba en que el Dios que representa también lo mira. Se supone que complace a Dios. A este nivel, el artista opera en el plano sacrificial -pues cuenta con que existen cosas, imágenes en este caso, que pueden suscitar el deseo de Dios"11. Efectivamente, los artistas bizantinos plasmaron una pantallaimagen de Cristo, pantalla-imagen que constituye una manera de articular, aunque no de representar, la mirada de Dios, que todo lo cubre en el mundo cristiano.

En paralelo con esto, Lacan destaca dos efectos que la pintura produce en el espectador. El primero de ellos es "el efecto pacificador, apolíneo, de la pintura" 12. Esta sensación se produce debido a que ante el cuadro, el espectador depone, como el pintor, la mirada. En principio, esto significa que deja de colocarse como eje de la representación. Pero para que sea verdaderamente pacificador, tiene que haber algo más. Como vimos, el pintor también depone la mirada, acto mediante el cual articula una mirada que huye en el punto de fuga. Al mismo tiempo, elabora un lugar desde el cual contemplar. La pacificación apolínea se debe no a un encuentro,

10 En Océano mar, Alessandro Baricco expone un argumento similar. En el pasado, Plassom era un pintor de retratos. Su secreto se encontraba en empezar por los ojos, y después el cuadro salía automáticamente. Pero en el momento en el que lo toma la novela, está intentando pintar el mar. Precisamente, sus dificultades se encuentran en el hecho de que no encuentra sus ojos. Así, se queda helado cuando otro personaje le revela que esos ojos son los barcos. En todo caso, el pintor se da cuenta de que lo visual se abre porque el paisaje nos mira. Baricco, A., Océano mar, Barcelona, Anagrama, 2012.

11 Ibidem, 119.

12 Ibidem, 108. 
porque no hay posibilidad de representar la mirada, sino a un acercamiento. Podemos comprenderlo con los mosaicos bizantinos de los que habla Lacan. Cuando el cristiano contempla a Cristo, depone la mirada, en tanto coloca esa mirada perdida, irrepresentable, en Dios. Por eso, el cuadro genera un acercamiento de la visión con la mirada. Pero también debemos decir que no todos los cuadros producen esta pacificación. Frente a los paisajes calmos de cierta pintura, hay otros evidentemente tensos, que tienen una atmósfera ominosa. Por eso Lacan encuentra un segundo efecto, que Recalcati destaca a partir de la anamorfosis. Su ejemplo es Los embajadores, de Hans Holbein. En la clase del 24 de febrero de 1964, Lacan lo describe de manera sucinta: dos hombres opulentos, con ropajes que ostentan su estatus social, se acodan en un mueble que exhibe los símbolos de las ciencias y las artes del trivium y el quadrivium y, debajo, pero en el centro, una mancha, algo que no se puede identificar. Cuando el espectador cambia de ángulo, por ejemplo cuando está por salir de la sala, la mancha se convierte en calavera. Lacan sostiene que se trata de una imagen fálica, en el sentido de que de pronto se erecta, pero también en tanto impone un corte a la vanidad de la vida. El hombre, podríamos decir, es una aventura en el vacío. Esta interpretación, que se encuentra en la primera lectura que Lacan propone del Barroco, se carga ahora de otra connotación. De frente, vemos la riqueza del mundo, pero también esa mancha, que nos punza y, en este sentido, nos mira; de costado, justo cuando la riqueza de la tela está por desaparecer, la mancha se convierte en calavera, poniendo de manifiesto que lo que organiza nuestro campo visual es el $-\Phi$, es decir, la falta central del deseo. Por cierto, Holbein no representa la mirada, porque ésta es irrepresentable, pero con el juego de la anamorfosis sí representa su desaparición en el campo de lo visual, representación ominosa porque significa cortar al sujeto de la plenitud en la que se creía identificado.

En todo este gran campo del arte, Lacan vuelve a situar el Barroco en un lugar central a través de la interpretación de Las Meninas que propone en El objeto del psicoanálisis. En las primeras clases, aborda el cuadro a través de los lineamientos sobre la pintura que había comenzado a elaborar en Los cuatro conceptos. Según señala Lacan, Las Meninas nos interpela porque, de pie frente a la tela, Velázquez parece estar a punto de concluir nuestro retrato. Pero a la vez, el pintor parece haber quedado cautivado por la Infanta, esa figura sobre la cual cae toda la luz. En este sentido, el espectador depone la mirada sobre el pintor, se obnubila por lo que éste está pintando, pero el pintor parece haberse concentrado en la hija del rey. Tras estas precisiones, Lacan profundiza sobre el verdadero sentido que se encuentra detrás de este juego de miradas. Velázquez, según recuerda en su clase, podría haber pintado el cuadro al colocar un espejo frente a la escena. De este modo, habría logrado pintarse al lado de la Infanta. En principio, Lacan discute esta hipótesis, porque el pintor era diestro y en el cuadro Velázquez aparece manejando el pincel con la mano 
derecha. Si se hubiera retratado utilizando un espejo, la figura tendría que haber sido zurda. Pero en la última clase reconoce que el efecto del cuadro se encuentra en que sugiere que delante de la escena, justo en el lugar donde nos paramos y donde están parados los reyes, existe aunque sea virtualmente un espejo. A partir de esta hipótesis, retoma su modelo óptico, transformado ya por su larga reflexión sobre la mirada. De acuerdo con el esquema, Velázquez se ha colocado en el ángulo correcto para apreciar la imagen que se forma en el espejo plano. Entonces dirige su mirada a la imagen de la Infanta. Por casualidad, ese personaje, con su vestido acampanado y su pelo rubio, recuerda casi a la perfección el florero del modelo de Lacan. Pero más allá de esta coincidencia asombrosa, la Infanta se presenta como objeto de deseo y por lo tanto como pivote para la identificación imaginaria del pintor. Así lo demuestra la centralidad de su figura y el hecho de que Velázquez la haya pintado en más de una oportunidad. Ahora bien, como predice en «Observación sobre el informe de Daniel Lagache», esta relación imaginaria se sostiene a partir de la mirada del Otro. En el cuadro, esa mirada está encarnada por los reyes, que aparecen borrosamente en el espejo que se encuentra detrás de la sala. En este sentido, delante de la escena, ejercen una mirada determinante, porque todos los personajes giran a su alrededor. Pero a la vez, el cuerpo de la pareja real parece haberse consumido como el cuerpo de la ninfa Eco, quedando en su caso únicamente la mirada. Este juego asombroso le permite a Lacan convertir a los reyes en el espejo plano. Velázquez mira hacia ellos pero no los ve, porque ellos se borran detrás de la imagen de la Infanta. Representantes de una monarquía en tránsito irremediable hacia la decadencia, orientan la mirada del pintor hacia esa figura. ¿Y qué encuentran, el pintor y el espectador, en la Infanta? Precisamente lo contrario de la decadencia: una figura iluminada por la promesa del porvenir.

Con este análisis de Las Meninas, Lacan demuestra de nuevo que el Barroco se anticipa al psicoanálisis. Pero ahora no se trata sólo de los juegos de las imágenes y las miradas que había encontrado en la primera formulación del modelo óptico. Al lado de esta cuestión, Lacan descubre que, por medio de Las Meninas, el siglo XVII logró pensar las paradojas de la percepción. Como todo pintor, Velázquez exterioriza su fantasía, que en su caso es el deseo de una España pujante. Pero superando a muchos pintores, también sugiere la mirada bajo la cual esa fantasía se produce. Como sabemos, la mirada es el objeto $a$, núcleo estructurante pero no estructurado del campo de la visión, por lo tanto perdido detrás de la pantalla. Pero Velázquez, apoyándose en esa época extraordinaria de la pintura que es el Barroco, articula todos los recursos técnicos, los saberes sobre la representación e incluso la geometría para lograr sugerir con el cuadro y por el cuadro la incidencia de la mirada. Lo más significativo es que con esto parece haber descubierto, seguramente sin saberlo, la imposibilidad del objeto $a$. Efectivamente, el pintor quiere hacer sentir el peso de la mirada, pero únicamente puede sugerirla con una esquirla imaginaria 
que la señala y la traiciona: no sabríamos nada de la mirada de los reyes, ni siquiera de que en el cuadro ellos están implicados, si Velázquez no hubiera dado esas pinceladas en el fondo de la sala, con las cuales los representa, situándolos en el registro imaginario y simbólico de la visión. Por cierto, están a punto de disolverse, pero sus figuras todavía están ahí como testimonio del objeto a y de su imposibilidad de representación. Para Lacan, la importancia del Barroco se encuentra en esta demostración pictórica de las paradojas de la mirada.

\section{El Barroco del cuerpo}

En la primera clase que le dedica a Las Meninas, Lacan recuerda la opinión de Luca Giordano (1634-1705) de que el cuadro es la teología de la pintura. En la última, indica que la Infanta está parada justo en el medio de la cruz que estructura el cuadro y unas palabras después destaca la cruz de la orden de Santiago que figura en el pecho del pintor. Esa cruz, recuerda Lacan, ha sido añadida por otro. Velázquez fue nombrado en la orden un año y medio después de terminar el cuadro y un año antes de morir. Según una leyenda, que Lacan reproduce para finalizar su análisis de Las Meninas, el que la estampó en su pecho, como muestra de gratitud, fue el propio Felipe IV. El cuadro, una genial combinación de destreza, sensibilidad e ingenio, está impregnado de religiosidad. Para Lacan, Dios ingresa al cuadro a través de Felipe IV. Monarca católico, pinta la cruz de Santiago y, sobre todo, encarna la mirada de ese Otro que es Dios. En El objeto del psicoanálisis, Lacan se queda con esta última interpretación de Las Meninas; seis años después, en la clase «Del barroco», que dicta en el seminario Aun, toma el impulso de ese gesto y presenta su análisis más completo del siglo XVII.

Aunque en esta oportunidad no revela sus referencias bibliográficas, elabora una lectura muy cercana a la que propone Werner Weisbach en El Barroco, arte de la Contrarreforma (1921)13. En ese volumen clásico, Weisbach sostiene que la cultura del siglo XVII puede comprenderse como una respuesta a los conflictos en los que había terminado el espíritu humanista del renacimiento europeo. El fin de la universalidad católica, las luchas religiosas, las guerras dinásticas de los soberanos y el asalto y saco de Roma por las fuerzas imperiales pusieron fin a la pasada confianza y amenazaron la estabilidad de los valores esenciales. Corrió por Europa un viento de escepticismo y, en consecuencia, "los hombres buscaron de nuevo en su propia intimidad y en la autoridad de la Iglesia apoyo y protección"14. Como res-

13 También formulé este vínculo entre Lacan y Weisbach en Iriarte, I., "Barroco, hermenéutica y modernidad I", Studia aurea, 5 (2011), Barcelona, Universitat de Girona-Universitat Autònoma de Barcelona, disponible en http://www.studiaaurea.com/articulo.php?id=197, pp. 71-97.

14 Weisbach, W., El Barroco, arte de la Contrarreforma, Madrid, Espasa-Calpe, 1948, p. 57. 
puesta, la Iglesia Católica definió una nueva política en el Concilio de Trento. Reunido entre 1545 y 1563, para Weisbach Trento no fue exclusivamente una reacción contra la Reforma, sino también una respuesta a los conflictos espirituales surgidos del colapso del humanismo. Ante esta situación, la Contrarreforma impulsó la conducción de los creyentes a los valores esenciales de la cristiandad y buscó transformar el pesimismo en "un fin positivo que satisficiese las necesidades espirituales"15. Para esto, reanudó la tradición dogmática de la escolástica, reforzó los elementos tradicionales de la enseñanza y cortó de raíz los abusos contra los cuales había reaccionado el protestantismo. Consecuente con esto, el Concilio subordinó el arte a los fines propagandísticos de la cristiandad.

En consonancia con Weisbach, Lacan sostiene que el Barroco es el arte de la Contrarreforma y demuestra su tesis estableciendo un contrapunto comparativo con el Renacimiento. Según señala en su clase, la recuperación renacentista de la Antigüedad dio como resultado que los cuadros se poblaran de politeísmo y que se impusiera la idea de que el mundo estaba hecho para el disfrute del hombre. El Concilio de Trento, repitiendo el gesto con que el cristianismo primitivo desalojó la cultura romana, barrió con aquella laica concepción hedonista de la vida y volvió a erigir la idea escolástica de que el mundo es un libro escrito por la mano de Dios. Imbuidos del espíritu contrarreformista, los artistas plásticos colocaron a Dios en el centro de la vida social y lo hicieron a través de la representación de su incidencia en el cuerpo de los seres humanos. Este propósito se concretó en primer lugar en las obras sobre los místicos. Como se advierte en El éxtasis de Santa Teresa de Bernini, este tipo de trabajos muestran el momento gozoso en el cual Dios interviene en el cuerpo. En segundo término, el espíritu contrarreformista se materializó en los trabajos sobre Cristo en la cruz. Para Lacan, "Cristo, aun resucitado, vale por su cuerpo"16, sentencia que hay que leer al abrigo de otra que la antecede en su discurso, en la cual señala que "El barroco es inicialmente la historieta, el anecdotario de Cristo"17. Para comprender estas frases, Weisbach vuelve a ser revelador. Según el historiador, hay un vínculo cercano entre la pintura religiosa y los ejercicios espirituales de Ignacio de Loyola. Como se sabe, los ejercicios se llevaban a cabo durante aproximadamente un mes, período en el cual los creyentes hacían oraciones y meditaban en silencio, representándose las etapas de la vida de Jesús, con un especial énfasis en las escenas de la tortura y la crucifixión. Según Weisbach, la dramática pintura religiosa del Barroco fue, en parte, una realización artística de estos ejercicios, mediante los cuales los pintores buscaron reimponer, dentro de una población en su mayoría analfabeta y apoyada por lo tanto en lo visual, la centralidad de Cristo en la vida social. Lacan concentra esta interpretación: la pintura del

\footnotetext{
15 Ibidem, 58.

16 Lacan, J., Seminario. Libro 20. Aun, Buenos Aires, Paidós, 2001, p. 137

17 Ibidem, 130.
} 
Barroco muestra la vida de Cristo como si fuera un anecdotario, pero también una historieta, colgando los cuadros de la Pasión. Así, los artistas plásticos centran a Dios a través de su manifestación en el cuerpo torturado de Jesús.

Para Lacan, la clave de la pintura barroca se encuentra, sin embargo, en aquello que no está representado. En ese arte que califica como obsceno, que muestra un amontonamiento de cuerpos que gozan aún en su sufrimiento, los artistas nunca representaron una sola cópula sexual:

En todo lo que se desprendió por efecto del cristianismo, en especial en arte -por eso voy a dar en el barroquismo ese que acepto que me encasqueten- todo es exhibición de cuerpos que evocan el goce, y créanme pues es el testimonio de alguien que acaba de regresar de una orgía de iglesias en Italia. Todo menos la copulación. No en balde no está presente. Está tan fuera de campo como lo está en la realidad humana, a la cual sustenta, empero, con los fantasmas con que está constituida. 18

Para Lacan, el arte del Barroco muestra el momento exacto en el cual el Otro se revela en el cuerpo como castración. Con esto, descubre la verdadera estructura, porque demuestra que el sujeto está arrojado a un mundo de la carencia, cuyo sentido sólo se encuentra en ese Otro que al fin y al cabo es Dios. Pero además lo hace porque se percata de que la intervención del Otro tiene como efecto la imposibilidad de la relación sexual. No hay relación sexual, sugiere el Barroco y ratifica Lacan, porque no existe complementariedad, unión real entre dos personas. Podemos pensar en ella, debido a que contamos con el mito de la unión simbiótica con la madre en la cual la imagen corporal forma un uno con su cuerpo. Como revela Lacan en el temprano Las formaciones del inconsciente (1957-1958), esa relación se basa por otra parte en el hecho de que el infante comprende a la madre como significante a partir de la pregunta sobre lo que ella desea y en la suposición inmediata de que él es el significado, falo imaginario de ese deseo. La castración separa ese vínculo: el significante paterno sustituye metafóricamente el significante de la madre, de manera tal que éste cae en el inconsciente ${ }^{19}$. Esta intervención opera

\footnotetext{
18 Ibidem, 138-139.

19 La castración se define como la separación que produce la ley del lenguaje al ensamblar al sujeto en su red. Lacan lo formula de manera sintética a través de la estructura de la metáfora, que retoma de la retórica de acuerdo con el esquema proposicional. Para recordarlo, podemos tomar una metáfora sencilla como rubí en lugar de labios. El análisis es el siguiente:

$$
\frac{\text { rubí }}{\text { rojo }} \frac{\text { rojo }}{\text { labios }}
$$

El rubí y los labios comparten el sema "rojo". Establecida la relación, el elemento repetido cae. Esto da como resultado la fórmula $\mathrm{S}(1 / \mathrm{s}$ '), es decir, la palabra "rubí" domina un significado abierto, que puede ser cubierto por diversos objetos. Esta misma idea regula su concepción de la castración. El infante concibe la pareja parental en términos significantes. A su vez, intuye que hay un significado que gira ahí. Si lo cubrimos con una x, la aparición del padre produce la siguiente metáfora:
} 
sobre el sujeto, separándolo de los objetos que lo unían a la madre, fundando como vimos la función del objeto $a$, pero a la vez opera sobre la madre, sentenciando que ella no tiene el objeto del deseo, lo cual quiere decir que está marcada por el lenguaje, paso inaugural del significante de una falta en el Otro (S (A)). Si la relación sexual no existe, esto se debe a que, a partir de la castración, los sujetos buscan en su partenaire algo que éste no tiene: del lado del hombre, esa parte caída que constituye el objeto $a$, del lado de la mujer, la función fálica y el vínculo con ese agujero en lo simbólico que plantea el significante de una falta en el Otro y en el cual punza lo real. En este sentido, no hay relación sexual, porque un sujeto se vincula con otro por intermedio del gran Otro que lo determina y lo sujeta al lenguaje. El Barroco es una forma religiosa de asumir este nudo de la estructura.

En Aun, Lacan radicaliza esta interpretación de la castración. Para esto, refuerza la diferencia simbólica, no biológica, entre lo femenino y lo masculino. Asimismo, entiende que el Barroco sigue dos caminos correlativos: el de la mística y el de Cristo en la cruz. Para abordar estas cuestiones, presenta el siguiente esquema de la sexuación:

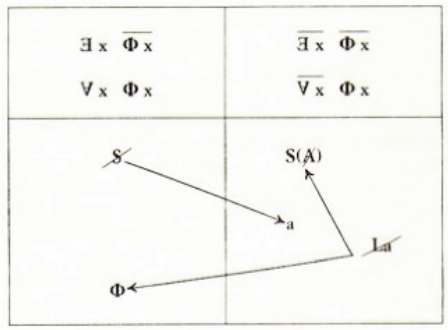

A la izquierda del esquema, se encuentran las fórmulas que definen la sexualidad masculina. Lacan demuestra que el hombre, como $\$$, se relaciona con el campo de la mujer únicamente a través del objeto de su fantasía: el $a$, sacrificio hecho al separarse de la madre. Asimismo, aunque está ligado al significante fálico $(\Phi)$, no tiene acceso directo a él. Luego se encuentran las dos fórmulas escritas arriba. La línea de abajo plantea que "el hombre en tanto todo se inscribe mediante la función fálica"20. Esto significa que ingresa al mundo tras la castración. Pero para hacerlo debe suponer, como señala en la fórmula de arriba, que existe uno que no esté castrado. Ese uno que no está castrado es Dios. Lacan explica el tema a partir de «Tótem y tabú» y «Moisés y la religión monoteísta» 21 . Para Freud, las religiones

$\frac{\text { Padre }}{\text { Madre }} \frac{\text { Madre }}{\mathrm{x}}$

Esto da como resultado que el significante de la metáfora del padre domina un significado que queda reprimido: $\mathrm{S}(1 / \mathrm{x})$. Asimismo, ese significado está abierto y es irreductible a la estructura.

20 Lacan 2001, op. cit. (nota 15), p. 96.

21 Cf. Freud, S., «Tótem y tabú», en Obras completas, tomo II, Madrid, Biblioteca Nueva, 1981, pp. 
pueden comprenderse como modalidades distintas de asumir la culpa por la muerte del padre de la horda primitiva. En los inicios de la cultura, los hijos que asesinaron al padre levantaron la religión totémica como búsqueda de expiación, estableciendo como ley la prohibición del incesto. Mucho tiempo después, cuando la marca de esa culpa quedó sepultada en el olvido, el pueblo judío la revivió al matar de nuevo al padre, en este caso a Moisés. El cristianismo, en fin, dio un paso más: Jesús, uno de los hijos del padre, asumió la culpa de todos sus hermanos y por eso se inmoló. Con esto, el padre de la horda primitiva fue revivido en la memoria colectiva. Lacan retoma esta reconstrucción de diversas maneras (en particular, demuestra con esto que Dios está muerto de entrada), pero lo importante en el marco del esquema de la sexuación es que, si todos los hombres se someten a la castración, hay uno, Dios o el padre de la horda primitiva, que no lo está. Se trata de la excepción a la castración, reconstrucción mítica que permite hablar de un ser absolutamente pleno. Pero para que ese mito viva, el hombre debe padecer un sacrificio concreto: debe inmolarse en la castración. Si el Barroco volvió a las fuentes de la catolicidad, fue en la medida en que representó de nuevo a Cristo como aquel que está en condiciones de salvar a Dios. Por esa razón, así como hay un lado masculino, hay en el siglo XVII una línea del arte que está centrada en la representación de su sufrimiento. En Aun, lo sintetiza con los siguientes términos, hablando de los evangelios como "la historieta de Cristo": "es cierto que la historieta de Cristo se presenta, no como la empresa de salvar a los hombres, sino a Dios. Ha de reconocerse que quien se encargó de esta empresa, Cristo, en este caso, pagó lo suyo, y es poco decir"22. La pintura barroca volvió a exhibir esta cuestión, restituyendo el cristianismo a sus fuentes primordiales, al exhibir al Cristo sufriente de la Pasión.

Pasemos ahora a la mujer. Según el cuadro, la mujer únicamente puede buscar la función fálica del lado del hombre. Por esta razón, le corresponden las dos fórmulas de la línea de arriba. Con la primera, Lacan sostiene que no existe excepción a la función fálica, es decir, no hay sujeto que no esté marcado por la castración. Sin embargo, la línea de abajo indica que las mujeres se colocan fuera de la función fálica. En esto no hay contradicción. Lacan sostiene que la función fálica se encuentra fuera del campo de la mujer, lo cual significa que por un lado escapa a la ley universal y por el otro debe apelar a ella para sostenerse subjetivamente. Esta doble característica lleva a Lacan a afirmar la controvertida idea de que la mujer no tiene vocación universal (no hay una definición universal de lo femenino) y que, por lo tanto, no existe, propuesta que resume al tachar el artículo definido. Ła mujer no existe, pero hay una multiplicidad de mujeres. Asimismo, esto significa que, desde el punto de vista de la ley universal, una mujer es no-toda. Con esto, Lacan pone de

1745-1850, y «Moisés y la religión monoteísta», en Obras completas, tomo III, Madrid, Biblioteca Nueva, 1981, pp., pp. 3241-3324.

22 Lacan 2001, op. cit. (nota 15), p. 131. 
manifiesto que siempre es algo más que la función fálica, que allí hay un exceso. Esto se encuentra representado por las dos relaciones que establecen las flechas. Por un lado, una mujer se vincula con la función fálica, colocada del lado de su partenaire. Sólo puede sostenerse a través de la referencia a una ley universal que le es exterior. Pero a la vez se vincula con el S (A). En Lacan, el significante de una falta en el Otro indica que no hay un Otro del Otro, es decir, no hay un lenguaje sobre el lenguaje. Por lo tanto, el significante de una falta en el Otro constituye la frontera o la bisagra de lo simbólico. Si la mujer se vincula con la función fálica, situada del lado del hombre, y tiene por lo tanto un goce fálico, al mismo tiempo accede a un goce específicamente femenino, que es este vínculo con el límite entre el lenguaje y lo real. Ła mujer no existe porque se vincula con este deseo abierto, suplementario, excesivo, que desborda el límite del lenguaje. En este sentido, accede a la verdad (el empalme del significante con lo real), pero no puede decir nada de eso.

Como vimos, del lado del hombre el Otro puede plantearse como Dios en tanto se trata de la excepción a la castración. Esto está ligado a la Pasión de Cristo: se trata de alguien que se inmola para demostrar la existencia del padre pleno. Por esa razón, el camino de lo masculino define en el Barroco esa línea de la pintura que se estructura alrededor del cuerpo sufriente de Jesús. Del lado de la mujer sucede otra cosa. Si bien no deja de remitirse a la función fálica, ella puede experimentar el borde entre lo simbólico y lo real. Ła mujer accede a la verdad, límite que conecta el lenguaje con el afuera. Si en el hombre Dios es un mito, en ta mujer es la mordedura del significante a lo real. Para Lacan, en el Barroco este campo define las obras de la mística religiosa. Como lo demuestra El éxtasis de Santa Teresa, la mística es una forma de goce. No se trata de un sacrificio para salvar a Dios, sino de una conexión, un alumbramiento, una experiencia con un deseo abierto y por lo tanto infinito. En este sentido, la mística conecta con algo imposible, irreductible, con el suplemento inarticulable de lo real.

En Aun, Lacan se coloca del lado del Barroco. Cabe agregar que lo hace en el campo más específico de la mística, perfilando su indagación por la vía femenina:

Estas jaculaciones místicas no son ni palabrería ni verborrea; son, a fin de cuentas, lo mejor que hay para leer - nota a pie de página: añadir los Escritos de Jacques Lacan, porque son del mismo registro. Con lo cual, naturalmente, quedarán todos convencidos de que creo en Dios. Creo en el goce de la mujer, en cuanto está de más. ${ }^{23}$

Pero hay una diferencia crucial entre el siglo XVII y este retorno al Barroco que propone Lacan. Mientras que los mártires y los místicos levantan su mirada a Dios, Lacan retoma la estructura para evacuar esa sustancia infinita y plena. Por la vía del hombre, es un mito elaborado a posteriori; por el de ta mujer, es el agujero de lo real; en cualquier caso, Dios es un efecto del lenguaje.

23 Ibidem, 92. Cursivas en el original. 


\section{Conclusiones}

A lo largo de su trabajo, Lacan deslinda los campos de lo imaginario, lo simbólico y lo real. En el primer tramo de su enseñanza, se ocupa del primero de estos registros, pero desde el principio se puede percibir el lugar dominante que ocupa el lenguaje. En el enfrentamiento del niño con el espejo, el eje que estabiliza la estructura es el significante que lo precipita en su imagen. En esta etapa, lo real aparece como la Cosa, madre primordial, caída del proceso de simbolización. En la época de Los cuatro conceptos y El objeto del psicoanálisis, Lacan retoma estos fundamentos, pero revisa su organización y profundiza algunas cuestiones. En primer lugar, abandona la centralidad de la Cosa y comprende lo real a partir del objeto $a$. En este marco, le da una mayor precisión a la diferencia entre la visión y la mirada. En Aun Lacan subraya, finalmente, que lo simbólico y lo imaginario se organizan en función del impacto del Otro en el cuerpo, impacto que se comprende como castración y por consiguiente como imposibilidad de la relación sexual. A partir de esto, diferencia las vías masculina y femenina mediante las cuales el sujeto puede asumir su relación imposible con lo real: en el primer caso a través del goce del objeto $a$, en el segundo a través de ese agujero no simbolizado que se encuentra en su cuerpo y que es irreductible a la estructura.

En estos tramos de su desarrollo teórico, Lacan establece, como vimos, distintas interpretaciones del Barroco. En los primeros años de su enseñanza, comprende el período como un arte del vacío, en el segundo como un arte de la mirada y en el tercero como un arte del cuerpo en tanto intervenido por el Otro. Pero debajo de los cambios interpretativos, hay una serie de constantes que quisiera recolectar para concluir:

1) Aunque en «Observación sobre el informe de Daniel Lagache» cita a algunos autores franceses, Lacan entiende que el Barroco pertenece a España e Italia.

2) En correlación con esto, es un arte católico, e incluso contrarreformista.

3) Sostiene, además, que el Barroco ha descubierto la estructura del sujeto.

4) Finalmente, lo comprende como un complejo artefacto mediante el cual los artistas intentaron acercarse a lo real.

En estas líneas finales, me parece oportuno subrayar que para Lacan el Barroco no representa de ninguna manera el conjunto de la cultura europea del siglo XVII. En este sentido, el Barroco debería interpretarse a partir de lo que, en el 1600, Lacan considera que se encuentra fuera de su estructura. En su obra, ese lugar lo ocupa el pensamiento de René Descartes. Lacan considera que Descartes es el fundador de la ciencia moderna. Según expone a lo largo de sus seminarios, esto se debe a que por primera vez ha separado saber y verdad. Para Lacan, el saber es la batería de los 
significantes, que se pueden amplificar, desarrollar mediante esquemas regulados, deducir unos de otros, de acuerdo con determinadas reglas, organizadas por ejemplo en una cientificidad. Pero una de las cosas que define la batería de los significantes es su incompletad. Esta incompletad no se debe a que el saber todavía no ha alcanzado el todo, sino a que la condición misma de lo simbólico es dejar un resto. En este marco, Lacan le asigna un lugar específico a la verdad: no es simplemente lo real, sino lo real en tanto está perpetuamente constituido como una pérdida del sujeto que habla. Si Descartes es el fundador de la ciencia moderna, esto se explica porque se apoya por primera vez en esta escisión entre saber y la verdad. Como señala Lacan, su movimiento consiste en colocar la verdad en Dios, acto que si por un lado garantiza el conocimiento, por el otro erradica la verdad de las preocupaciones de la ciencia. De este modo, el saber puede concentrarse en la ampliación indefinida de los significantes.

Lacan distingue el Barroco del pensamiento cartesiano. Por supuesto, esto no impide que tengan un suelo conceptual compartido. Tanto Descartes como el Barroco descubren la estructura del sujeto en tanto se apoyan en su escisión constitutiva. En ambos casos, esa escisión se revela por el hecho de que la verdad y el saber están irremediablemente separados. En el arte de la Contrarreforma, el sujeto y el mundo sólo tienen sentido a partir de la intervención de Dios, intervención que, sin embargo, y como demuestran los místicos, resulta incomprensible. En el pensamiento cartesiano, el hombre desarrolla extensamente el saber, pero bajo la condición de que su verdad se encuentre fuera de su alcance. Pero si para ambos el sujeto tiene su fundamento irrecuperable en el Otro, se diferencian en la articulación distinta que producen entre saber y verdad. El pensamiento cartesiano se libera de la verdad depositándola en Dios, de manera tal que puede desarrollar su saber; el Barroco, en cambio, le da un giro al saber para que éste busque en el mundo la manifestación de la verdad divina. Bajo la mirada de Lacan, el siglo XVII se encontraría entonces polarizado por un saber sin preocupación por la verdad y un saber que lo único que busca es su iluminación. Si la ciencia moderna produce un saber y un resto, el Barroco se puede comprender como un síntoma: asume a su cargo la cuestión de la verdad, no porque logre decir qué es, sino porque articula su enigma al volver a las fuentes de la cristiandad.

Como dije al principio de este trabajo, el Barroco se ha convertido en un objeto que acompaña el pensamiento moderno. A partir de lo que vimos, podemos comprobar esta tesis al menos en la obra de Lacan. Sin lugar a dudas, Lacan se incluye en la ciencia moderna. En «La ciencia y la verdad», señala de manera enérgica que el psicoanálisis es hijo de la ciencia, como lo demuestra el hecho de que Freud se adentró en los sueños empujado por una voluntad científica ${ }^{24}$. Pero a la vez añade

24 Se trata de la primera clase de El objeto del psicoanálisis, cuya transcripción aparece en los Escritos. Cf. Lacan 1999, op. cit. (nota 5), pp. 834-856. 
que el psicoanálisis le da un giro a la ciencia en tanto asume el retorno de la verdad, es decir, la pérdida de lo real como núcleo estructurante y no estructurado del sujeto. ¿No es esto lo que se encuentra ya en el siglo XVII? Efectivamente, en ese momento crucial se funda la ciencia como olvido de la verdad y reaparece la preocupación de la verdad en el arte del Barroco. Pero mientras que en el 1600 esta preocupación se plasma en una organización religiosa, en el siglo XX se articula desde la ciencia a partir del psicoanálisis. En este sentido, el Barroco anticipa el discurso lacaniano, pero el discurso lacaniano no se reduce a él. Lacan subvierte la ciencia, como el Barroco, pero se queda del lado de la ciencia, en la medida en que, como comenta Alain Lemosof, abandona la causa final, escatológica, en la que en última instancia se funda el sentido religioso, y se apoya en la causa material, es decir, en el material del significante 25 . Por la vía de este movimiento, recupera la preocupación por la verdad, pero a la vez vacía de todo contenido y de toda trascendencia la estructura del sujeto. La consecuencia más importante es que comprende a Dios como Otro. No se trata de una esencia, sino de un lugar operatorio de la palabra. Al mismo tiempo, la causa material del sujeto se encuentra en el rasgo unario, situado en el campo del Otro, rasgo que comienza el desfiladero del significante y punto en el cual se funda la verdad, en tanto desalojo de lo real. Sin duda, como en la religión, esa verdad es universal, pero sólo en su necesidad estructural, porque le corresponde a cada sujeto en particular. Por otra parte, ese rasgo unario se coloca en el campo del Otro, como en la religión, pero ese Otro no puede saber nada de eso. De acuerdo con Lacan, el pensamiento moderno se ocupa del Barroco en tanto es un objeto que se resiste al saber científico, pero únicamente tiene interés en el marco de la ciencia, porque orienta un vuelco en las formas habituales de pensar.

Por último, la posición de Lacan permite orientar dos hipótesis encadenadas sobre las diversas recuperaciones del Barroco que se hicieron en el campo de la teoría y de la literatura a lo largo del siglo XX. En primer lugar, el Barroco retorna porque él mismo es un retorno del problema de la verdad. En segundo lugar, el extenso período que separa los siglos XVII y XX supone que de ninguna manera ese problema se articula en los mismos términos que durante la Contrarreforma. Como se advierte en Lacan, la recuperación del Barroco se basa en el hecho de que, desde la ciencia, el psicoanálisis intenta interrogar la verdad. Por lo tanto, la tarea de la crítica sería identificar, no la recuperación en sí del Barroco, sino el modo mediante el cual los campos modernos del arte, la filosofía y la literatura vuelven a interrogarse sobre una verdad que se encuentra en el núcleo de sus propios saberes como paso previo a esa recuperación. Pero, por supuesto, esto quedará para otro trabajo.

25 Lemosof, A., «El objeto del psicoanálisis», E Safoun, M. (dir.), Lacaniana II, Buenos Aires, Paidós, pp. 97-98. 